University of Wollongong

Research Online

Australian Institute for Innovative Materials -

Papers

Australian Institute for Innovative Materials

$1-1-2011$

\title{
Nanoscale condensation of water on self-assembled monolayers
}

Michael James

Australian Nuclear Science and Technology Organisation (ANSTO)

Tamim A. Darwish

Australian Nuclear Science and Technology Organisation (ANSTO)

Simone Ciampi

University of New South Wales, sciampi@uow.edu.au

Sven O. Sylvester

University of New South Wales

Zhaoming Zhang

Australian Nuclear Science and Technology Organisation (ANSTO)

See next page for additional authors

Follow this and additional works at: https://ro.uow.edu.au/aiimpapers

Part of the Engineering Commons, and the Physical Sciences and Mathematics Commons

Research Online is the open access institutional repository for the University of Wollongong. For further information contact the UOW Library: research-pubs@uow.edu.au 


\title{
Nanoscale condensation of water on self-assembled monolayers
}

\begin{abstract}
We demonstrate that water is almost universally present on apparently dry self-assembled monolayers, even on those considered almost hydrophobic by conventional methods such as water contact goniometry. The structure and kinetics of nanoscale water adsorption onto these surfaces were investigated using X-ray and neutron reflectometry, as well as atomic force microscopy. Condensation of water on hydrophilic surfaces under ambient conditions formed a dense sub-nanometre surface layer; the thickness of which increased with exponentially limiting kinetics. Tapping mode AFM measurements show the presence of nanosized droplets that covered a small percentage $(\sim 2 \%)$ of the total surface area, and which became fewer in number and larger in size with time. While low vacuum pressures ( $10-8 \mathrm{bar})$ at room temperature did nothing to remove the adsorbed water from these monolayers, heating to temperatures above $65^{\circ} \mathrm{C}$ under atmospheric conditions did lead to evaporation from the surface. We demonstrate that water contact angle measurements are not necessarily sensitive to the presence of nanoscale adsorbed water and do not vary with time. For the most part they are a poor indicator of the kinetics and the amount of water condensation onto these surfaces at the molecular level. In summary, this study reveals the need to exclude air containing even trace amounts of water vapor from such surfaces when characterizing using techniques such as X-ray reflectometry. 2011 The Royal Society of Chemistry.
\end{abstract}

Keywords

self, assembled, nanoscale, monolayers, condensation, water

Disciplines

Engineering | Physical Sciences and Mathematics

Publication Details

James, M., Darwish, T. A., Ciampi, S., Sylvester, S. O., Zhang, Z., Ng, A., Gooding, J. Justin. \& Hanley, T. L. (2011). Nanoscale condensation of water on self-assembled monolayers. Soft Matter, 7 (11), 5309-5318.

\section{Authors}

Michael James, Tamim A. Darwish, Simone Ciampi, Sven O. Sylvester, Zhaoming Zhang, Albert Ng, J Justin Gooding, and Tracey L. Hanley

This journal article is available at Research Online: https://ro.uow.edu.au/aiimpapers/1855 


\title{
Soft Matter
}

\section{Nanoscale condensation of water on self-assembled monolayers $\dagger$}

\author{
Michael James, ${ }^{* a b}$ Tamim A. Darwish, ${ }^{a}$ Simone Ciampi, ${ }^{b}$ Sven O. Sylvester, ${ }^{b}$ Zhaoming Zhang, ${ }^{a}$ Albert Ng, ${ }^{b}$ \\ J. Justin Gooding ${ }^{b}$ and Tracey L. Hanley ${ }^{a}$
}

\author{
Received 18th January 2011, Accepted 22nd March 2011 \\ DOI: $10.1039 / \mathrm{c} 1 \mathrm{sm} 05096 \mathrm{f}$
}

\begin{abstract}
We demonstrate that water is almost universally present on apparently dry self-assembled monolayers, even on those considered almost hydrophobic by conventional methods such as water contact goniometry. The structure and kinetics of nanoscale water adsorption onto these surfaces were investigated using X-ray and neutron reflectometry, as well as atomic force microscopy. Condensation of water on hydrophilic surfaces under ambient conditions formed a dense sub-nanometre surface layer; the thickness of which increased with exponentially limiting kinetics. Tapping mode AFM measurements show the presence of nanosized droplets that covered a small percentage $(\sim 2 \%)$ of the total surface area, and which became fewer in number and larger in size with time. While low vacuum pressures $\left(\sim 10^{-8}\right.$ bar $)$ at room temperature did nothing to remove the adsorbed water from these monolayers, heating to temperatures above $65^{\circ} \mathrm{C}$ under atmospheric conditions did lead to evaporation from the surface.

We demonstrate that water contact angle measurements are not necessarily sensitive to the presence of nanoscale adsorbed water and do not vary with time. For the most part they are a poor indicator of the kinetics and the amount of water condensation onto these surfaces at the molecular level. In summary, this study reveals the need to exclude air containing even trace amounts of water vapor from such surfaces when characterizing using techniques such as X-ray reflectometry.
\end{abstract}

\section{Introduction}

Experience tells us that the ability of water vapour to condense on a material depends on a range of factors including temperature, relative humidity of the atmosphere and the hydrophobicity of the exposed surface. This study demonstrates that nanoscale water is almost universally present at the molecular level on apparently "dry" surfaces under ambient conditions. The implications are profound for nanoscale electronics, gas-phase sensors and devices as well as processes that occur at surfaces on the nanoscale, both in the laboratory and in nature. Molecular self-assembly processes are essential both in biology and in the chemical modification of inorganic surfaces to produce sensors ${ }^{1}$ and molecular electronics. ${ }^{2}$ The ability of proteins to fold depends not only on the relative arrangement of hydrophobic and hydrophilic amino acid residues, but also on their interactions with water. ${ }^{3}$ Interfacial water has also been of significant recent interest in order to understand its role in the prevention of bio-fouling of protein-resistant SAMs with applications for diagnostics, contact lenses or implantable medical devices. ${ }^{\mathbf{4 - 1 0}}$

\footnotetext{
a Australian Nuclear Science and Technology Organisation (ANSTO), Locked Bag 2001, Kirrawee DC, NSW, 2232, Australia.E-mail: mja@ ansto.gov.au; Fax: +6129717 3606; Tel: +61297179299

${ }^{b}$ School of Chemistry, University of New South Wales, Kensington, NSW, 2052, Australia

$\dagger$ Electronic supplementary information (ESI) available. See DOI $10.1039 / \mathrm{c} 1 \mathrm{sm} 05096 \mathrm{f}$
}

A number of authors have previously studied the interface between condensed water and highly ordered hydrophobic and hydrophilic surfaces. The reviews by Israelachvili and Wennerström ${ }^{11}$ discuss the role of hydration and water structure in biological and colloidal systems, while Verdaguer et al. ${ }^{12}$ detail the considerable attention given to the study of the structure of condensed water films on metals, metal oxides and self-assembled monolayers at cryogenic temperatures. Numerous experimental techniques have been used in the study of hydrophilicity and viscosity of liquid-like and ice-like interfacial water under different conditions such as confinement. Techniques include: neutron reflectometry, ${ }^{13}$ high-energy synchrotron X-ray reflectometry, ${ }^{14}$ infrared spectroscopy, ${ }^{15} \mathrm{AFM}^{16}$ and interfacial force microscopy, ${ }^{17,18}$ phase-sensitive sum-frequency vibrational spectroscopy, ${ }^{19-22}$ contact angle measurements, ${ }^{23}$ forced dewetting, ${ }^{24}$ and molecular dynamics simulations. ${ }^{5,6,25,26}$ Despite these studies, there is still much debate as to whether water is present as high viscosity, ice-like water or low viscosity, liquid-like water, as well as issues such as the existence of "nanobubbles" at the surface of hydrophobic SAMs. ${ }^{13,27}$ Further details of such studies may be found in the review by Goertz and Moore. ${ }^{28}$

The nature of water adsorbed from the atmosphere onto a range of hydrophobic and hydrophilic surfaces including metal oxides, minerals and polymers has also been investigated. Organization of water into an ordered layer on mica surfaces for example has been extensively studied, and recently Spagnoli et $a l^{29}$ were able to image an ice-like layer of water molecules on 
mica under ambient conditions using AFM. Studies of water adsorption on hydrogen-terminated $\mathrm{Si}(111)^{30,31}$ found that water-water interactions were stronger than water-substrate interactions. Studies of adsorbed water layers on hydrophilic silicon oxide ${ }^{32,33}$ revealed different structures were formed depending on the level of relative humidity $(\mathrm{RH})$, with an ice-like water monolayer observed below 30\% $\mathrm{RH}$, an additional transitional monolayer of water on the ice-like base for $\mathrm{RH}$ between $30 \%$ and $60 \%$, and liquid water at the interface with air for higher values of RH. Although the evolution of these water layers with time was not followed, this study revealed 10 monolayers (with a thickness of $\sim 28 \AA$ ) were present after exposure to $100 \%$ relative humidity.

Studies of water adsorption from the vapour phase onto SAMs are relatively less common. Rudich et al. investigated the wetting of hydrophobic SAMs formed using trichlorosilane molecules of different chain lengths on $\mathrm{SiO}_{2}$ surfaces. ${ }^{34}$ Their investigations indicated that water adsorption was reversible and also depended on the relative humidity. The surface roughness was found to be a key factor relating to how water arranged on these surfaces. In the case of rough or corrugated surfaces, water was found to penetrate irregularities allowing stronger interactions with the surrounding chains, and a higher probability of binding than on otherwise very smooth hydrophobic surfaces. This small amount of bound water enabled further adsorption, ultimately giving rise to clusters or micro-droplets on the surface. Although primarily a study on the forced dewetting of water drops on SAMs by shear forces, Tiani et al. also used ellipsometry to note the presence of $\sim 3 \AA$ thick adsorbed water films (formed in a 100\% water-vapour saturated environment) on carboxylic acid and alcohol-terminated monolayers formed on roughened silver substrates. ${ }^{24}$

In the absence of extensive experimental investigations, computational studies such as those by Szori et al. ${ }^{35,36}$ have shed significant light on the interactions between hydrophobic and hydrophilic thiol-based SAMs on gold, with atmospheric water at a range of vapour pressures at $300 \mathrm{~K}$. Their grand canonical Monte Carlo calculations revealed essentially no water adsorption on hydrophobic alkyl-terminated surfaces over the entire range of chemical potentials up to the point of saturation, where water condensation occurred. In contrast, they found that water readily adsorbed on a hydrophilic $\mathrm{C} 7-\mathrm{COOH}$ SAM even at low vapour pressures.

Studies of molecular switching of surface bound photo-active molecules have revealed unexpected results that are most likely the result of adsorbed water acting in concert with (or sometimes against) the desired stimulus. Siewierski et $a .^{37}$ for example examined the photo-isomerization of azobenzene molecules bound to a siloxane SAM on silicon using X-ray reflectometry. The expected behaviour of this system upon illumination with UV light was a reduction in the film thickness of $\sim 3 \AA$ associated with a cis-trans isomerization of the azobenzene. X-ray reflectometry showed an unexplained $1 \AA$ increase in the film thickness upon UV illumination. Our own studies of photochromic molecules bound to hydrophilic SAMs clearly demonstrate that adsorbed water masks the observation of the molecular switching that is the focus of such studies. ${ }^{38}$

In this report we demonstrate that molecular water condenses onto a range of apparently dry self-assembled monolayers of differing hydrophilicity under ambient conditions; and using the combination of reflectometry and AFM we have explored the formation and nature of these nanoscale water layers with subangstrom precision. Moreover, we show that conventional measures of hydrophilicity such as water contact angle measurements are not necessarily a useful indicator of the interaction of water with a surface at the molecular level.

\section{Experimental}

\section{Materials}

All chemicals, unless noted otherwise, were of analytical grade and used as received. Chemicals used in surface modification procedures were of high purity ( $\geq 99 \%)$. Both 100 -oriented and 111-oriented silicon wafers were used in this study. Si(100) wafers were prime grade, p-type (boron-doped), $500 \pm 25 \mu \mathrm{m}$ thick, $<0.01 \Omega \mathrm{cm}$ resistivity (Siltronix, S.A.S., Archamps, France). Si (111) wafers were prime grade, $\mathrm{p}$-type (boron), $1 \mathrm{~mm}$ thick and $1-10 \Omega \mathrm{cm}$ resistivity (M.M.R.C. Pty Ltd). Further details can be found in the ESI $\dagger$.

\section{Assembly of $\omega$-functionalized monolayer surfaces (SAM-1-SAM-7)}

Hydride-terminated surfaces were cleaned and functionalised via hydrosilylation of 1-alkene (1-5) or 1-alkyne (6-7) molecules, according to the process illustrated in Scheme 1 and following the methods reported in several previous studies. ${ }^{39-46}$ Specific details of each reaction are given in the ESI $\dagger$, and described in general detail below. Silicon wafers were heated in xylene $\left(130{ }^{\circ} \mathrm{C}\right.$ for 40 minutes), before being rinsed thoroughly with ethanol and Milli- $Q^{\text {TM }}$ water. Wafers were then cleaned using "piranha" solution (concentrated sulfuric acid $/ 30 \%$ hydrogen peroxide, $3: 1 \mathrm{v} / \mathrm{v}$ ) at $90{ }^{\circ} \mathrm{C}$ for 1 hour and rinsed again thoroughly with Milli- $\mathrm{Q}^{\mathrm{TM}}$ water. Silicon surfaces were hydrogen-terminated by immersion into either deoxygenated ammonium fluoride or hydrofluoric acid solutions. Wafers were dried with nitrogen gas and transferred without any rinsing to a pre-dried Schlenk flask under inert atmosphere.

The desired reagent (1-7) was either used neat $(c a .3 \mathrm{~mL})$ or dissolved in dry mesitylene; degassed using five freeze-pumpthaw cycles and transferred under nitrogen to the Schlenk flask

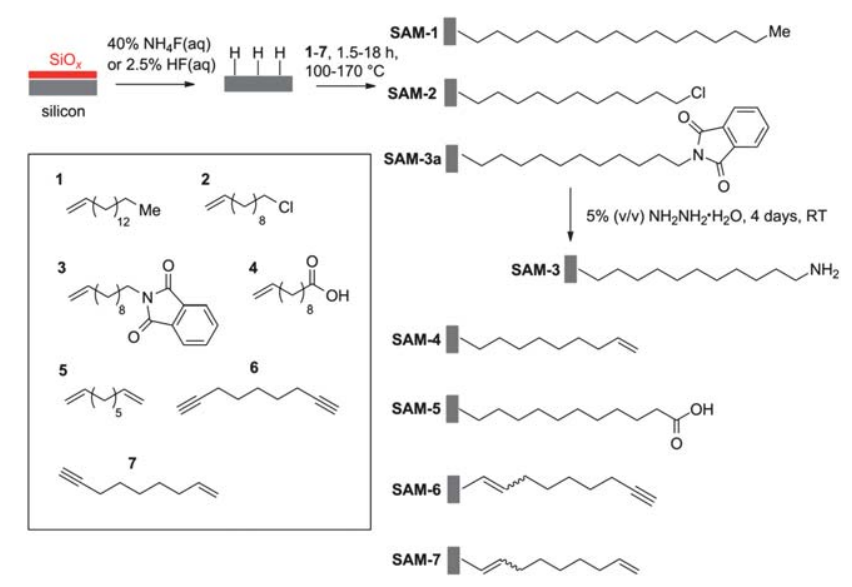

Scheme 1 Molecular self-assembly on silicon by $\omega$-functionalized 1 -alkene and 1-alkyne reagents. 
containing the freshly hydrogen-terminated silicon wafer. The flask was immersed in an oil bath at $100-170{ }^{\circ} \mathrm{C}$. After $15-$ 18 hours the flask was cooled to room temperature, opened to atmosphere and the sample cleaned by rinsing several times with hot dichloromethane, anhydrous ethyl acetate and ethanol. Following cleaning, samples were stored under dry argon or nitrogen prior to measurement.

\section{Water contact angle goniometry measurements}

Water contact angle measurements were made using a RaméHart 200-F1 goniometer. Samples were prepared in triplicate with at least three separate spots being measured for each sample. Images were analyzed using the low-bond axisymmetric drop shape analysis (LBADSA) method of Stalder et $a l .{ }^{47}$ and is based on the fitting of the Young-Laplace equation to the image data. The reproducibility of these measurements was $\pm 3^{\circ}$.

\section{Atomic force microscopy (AFM)}

All AFM measurements were acquired in tapping-mode in air using a Dimension 3000 (Digital Instruments) and commercially modified $\mathrm{Si}_{3} \mathrm{~N}_{4}$ cantilevers. Several images were taken such that the parameters of force, tip frequency, scan size, and scanning speed could be optimally adjusted for best imaging. All measurements were performed at room temperature and relative humidity $55 \%$, and the laser used for detecting the cantilever deflection had a minimal effect on the temperature of the sample under the cantilever. The height distribution was determined by cross-section analysis using the default Digital Instruments (Version 4.31, Rev B.) software.

\section{X-ray photoelectron spectroscopy}

X-ray photoelectron spectroscopy measurements were performed on an ESCALAB 220iXL. Monochromatic Al $\mathrm{K} \alpha$ $\mathrm{X}$-rays $(1486.6 \mathrm{eV})$ incident at $58^{\circ}$ to the analyzer lens were used to excite electrons from the sample. Emitted photoelectrons were collected on a hemispherical analyzer with a multi-channel detector at a takeoff angle of $90^{\circ}$ from the plane of the sample surface. The analyzing chamber operated below $10^{-9} \mathrm{mbar}$ and the spot size was approximately $1 \mathrm{~mm}^{2}$. The resolution of the spectrometer was $\sim 0.6 \mathrm{eV}$. All energies are reported as binding energies in $\mathrm{eV}$ and referenced to the $\mathrm{C} 1 \mathrm{~s}$ signal (corrected to $285.0 \mathrm{eV}$ ). Survey scans were carried out selecting $100 \mathrm{~ms}$ dwell time and an analyzer pass energy of $100 \mathrm{eV}$. High-resolution scans were run with a $0.1 \mathrm{eV}$ step size, a dwell time of $100 \mathrm{~ms}$ and the analyzer pass energy set to $20 \mathrm{eV}$. After background subtraction using the Shirley routine, spectra were fitted with a convolution of Lorentzian and Gaussian profiles as described previously. ${ }^{40}$ The ratios of the integrated areas for the $\mathrm{C} 1 \mathrm{~s}$ and $\mathrm{N}$ 1s emissions were each normalized for their elemental sensitivity. ${ }^{48}$

\section{$\mathrm{X}$-ray reflectometry $(\mathrm{XRR})$}

$\mathrm{X}$-ray reflectivity profiles of self-assembled monolayers on $\mathrm{Si}$ were measured under ambient conditions $\left(30{ }^{\circ} \mathrm{C}\right.$ and $40 \%$ relative humidity) on a PANalytical Ltd X'Pert Pro Reflectometer using $\mathrm{Cu} \mathrm{K} \alpha \mathrm{X}$-ray radiation $(\lambda=1.54056 \AA)$. The $\mathrm{X}$-ray beam was collimated using a Göbel mirror with a $0.1 \mathrm{~mm}$ slit and a postsample parallel collimator. Reflectivity data were collected over the angular range $0.05^{\circ} \leq \theta \leq 5.00^{\circ}$, with a step size of $0.010^{\circ}$ and counting times of $10 \mathrm{~s}$ per step. In order to obtain the quality of data necessary for this study, highly reproducible instrumentation is required with a stable $\mathrm{X}$-ray source and accurate encoding of the angle of the X-ray beam and detector with respect to the sample. Once exposed to air, alignment of the sample on the X-ray reflectometer took approximately 10 minutes prior to measurement. In situ heating of samples was carried out using a SEM Pty Ltd stirrer hotplate. Structural parameters of the prepared surfaces were refined using the MOTOFIT reflectivity analysis software ${ }^{49}$ with reflectivity data as a function of the momentum transfer vector normal to the surface $Q=4 \pi(\sin \theta) / \lambda$. The Levenberg-Marquardt method was selected to minimize $\chi^{2}$ values in the fitting routines. Single-layer or two-layer models were used to fit the observed data.

\section{Neutron reflectometry}

Neutron reflectivity data were measured using a freshly prepared $\mathrm{Si}-\mathrm{C}_{10} \mathrm{H}_{20} \mathrm{COOH}$ monolayer (SAM-5) using the Platypus timeof-flight neutron reflectometer ${ }^{50,51}$ at the OPAL $20 \mathrm{MW}$ research reactor (Australian Nuclear Science and Technology Organisation, Sydney). $23 \mathrm{~Hz}$ neutron pulses $(2.8 \AA \leq \lambda \leq 18.0 \AA$ ) were generated using a disc chopper system in the high-flux, low resolution mode $(\Delta \lambda / \lambda=7 \%)$ and recorded on a 2-dimensional helium-3 neutron detector. Reflected beam spectra were collected at $0.5^{\circ}$ for 1 hours $(0.3 \mathrm{~mm}$ slits $), 2.0^{\circ}$ for 2 hours ( $1.2 \mathrm{~mm}$ slits) and $3.5^{\circ}$ for 4 hours $(2.0 \mathrm{~mm}$ slits $)$ respectively. Direct beam measurements were collected under the same collimation conditions for 1 hour each. The sample was measured initially under dry $\mathrm{N}_{2}$, following 3 cycles of evacuation and purging. Following this measurement, the chamber was opened and a reservoir of $100 \mathrm{~mL}$ liquid $\mathrm{D}_{2} \mathrm{O}$ was placed adjacent to the sample. The air was removed via 3 cycles of evacuation and purging with dry nitrogen, and the sample was left under vacuum to equilibrate with $\mathrm{D}_{2} \mathrm{O}$ vapour for 72 hours prior to measurement. Structural parameters for these surfaces were also refined from these data using the MOTOFIT reflectivity analysis software. $^{48}$

\section{Results and discussion}

The composition and quality of the self-assembled monolayers (SAM-1-SAM-S6) were examined using X-ray photoelectron spectroscopy (Fig. S1-S6, ESI $\dagger$ ) and confirm the presence of high quality monolayer surfaces with the appropriate molecular functionality. XPS analysis of the monolayer SAM-7 prepared from 1-nonyne-8-ene has been previously reported ${ }^{39}$ and was found to have a $2: 1$ ratio of alkene to alkyne surface functionality. In almost all cases little detectable photoemission in the 102-104 eV region was observed, indicating dense monolayers and negligible oxidation of the underlying silicon substrates.

\section{Indication of macroscopic hydrophilicity by water contact angle goniometry}

Fig. 1 shows water drops on the hydrophobic methyl-terminated monolayer (SAM-1), the hydrophilic carboxylic acid-terminated 
monolayer (SAM-5) and the acetylene-terminated monolayer (SAM-6). Water contact angles for these surfaces were found to be $101^{\circ}, 50^{\circ}$ and $82^{\circ}$ respectively (Table 1 ) and agree with previously reported values. ${ }^{23,52,41}$

Table 1 lists the measured water contact angles for all of the surfaces investigated. Hydrophilic surfaces are considered to have water contact angles $<90^{\circ}$ and hydrophobic surfaces have contact angles $\geq 90^{\circ}$. Of the monolayer surfaces characterised in this study, only the methyl-terminated $\mathrm{Si}-\left(\mathrm{CH}_{2}\right)_{15}-\mathrm{CH}_{3}$ (SAM-1, $\left.101^{\circ}\right)$ and the chloro-terminated $\mathrm{Si}-\left(\mathrm{CH}_{2}\right)_{11}-\mathrm{Cl}\left(\mathbf{S A M}-2,9^{\circ}\right)$ met the definition of hydrophobic. All of the other surfaces can be considered classically hydrophilic.

We note that although a value of $c a . \sim 108^{\circ}$ is generally accepted as the standard reference value for methyl-terminated monolayers, values ranging between $110^{\circ}$ and $95^{\circ}$ have been reported for octadecyltrichlorosilane (OTS) monolayers on $\mathrm{SiO}_{2}{ }^{53-56}$ and are consistent with the value of $101^{\circ}$ observed for SAM-1. The contact angle for the amino-terminated SAM-3 $\left(52^{\circ}\right)$ was similar to that observed by Böcking et al. $\left(56^{\circ}\right),{ }^{43}$ generated by the removal of protecting tert-butyloxycarbonyl groups from the distal end of the SAM. Although significantly lower than the methyl-terminated $\mathrm{Si}-\left(\mathrm{CH}_{2}\right)_{15}-\mathrm{CH}_{3}$ surface (SAM-1), the olefin-terminated $\mathrm{Si}-\left(\mathrm{CH}_{2}\right)_{7}-\mathrm{CH}=\mathrm{CH}_{2}$ surface (SAM-4, 78 ${ }^{\circ}$ and the mixed monolayer produced from 1-nonyne-8-ene (SAM-7, 79 $)^{39}$ were essentially the same, and only slightly more hydrophilic than the acetylene-terminated monolayer (SAM-6, 82 ${ }^{\circ}$ ).

Water contact angles were also measured for a series of freshly prepared acetylene-terminated monolayers (SAM-6) as a function of time following exposure to ambient conditions. Measurements were made on a freshly exposed surface, as well as on other samples after 12, 24, and 72 hours of exposure. Observed contact angles showed essentially no variation (ranging between $79^{\circ}$ and $82^{\circ}$ ), and were not found to decrease with time in response to nanoscale water uptake on the self-assembled monolayer.

\section{Structural characterization of freshly prepared surfaces using X-ray reflectivity}

$\mathrm{X}$-ray reflectivity is an extremely powerful tool for the investigation of self-assembled monolayers bound to silicon.

This stems from the capacity to measure the thickness of such films with atomic resolution, and the high contrast in scattering length density (SLD) of the organic molecules in the SAM $\left(\mathrm{SLD} \approx 1 \times 10^{-5} \AA^{-2}\right)$ compared to air $(\mathrm{SLD}=0)$ and the silicon substrate $\left(\mathrm{SLD}=2.01 \times 10^{-5} \AA^{-2}\right)$. The average surface

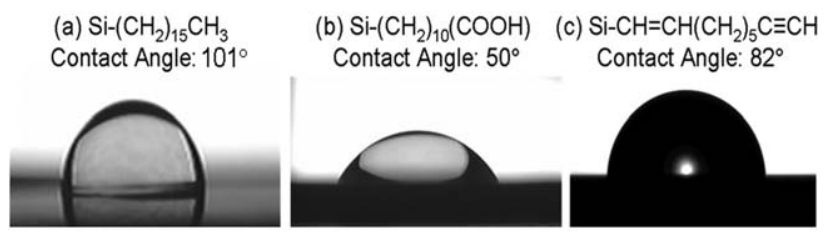

Fig. 1 Water contact angle measurements on (a) the hydrophobic alkylterminated monolayer (SAM-1), (b) the hydrophilic carboxylic acidterminated monolayer (SAM-5) and (c) the dialkyne functionalized monolayer (SAM-6). roughness $(\sigma)$ of these monolayers can also be precisely determined using this technique. The thickness of the film can lead to determination of the average chain canting angle of the molecules within the SAM. The film thickness, in concert with the refined SLD, can also be used to establish the area per molecule in the monolayer.

Refined structural parameters for SAM-1-SAM-7, determined from X-ray reflectivity data collected in the first 90 minutes after exposure to air, are listed in Table 1. With the exception of SAM4, all were found to be densely packed monolayers with molecular footprints between 17 and $27 \AA^{2}$. Chain canting angles for these monolayers range between $43^{\circ}$ and $59^{\circ}$. These structural parameters are consistent with earlier reports for such monolayers produced on hydride-terminated silicon surfaces via reaction with 1-alkenes ${ }^{4-45}$ and 1-alkynes. ${ }^{39,41}$

X-ray reflectivity data for SAM-4, formed by the reaction of 1,8-nonadiene $\mathbf{5}$ with hydride-terminated silicon, revealed a thicker film (14.4(1) $\AA$ ) than could be expected for a monolayer of the dialkene. Although the SLD for this film $(11.7(1) \times$ $\left.10^{-6} \AA^{-2}\right)$ is consistent with a fully dense monolayer, the relatively large roughness $(\sigma=6.7(1) \AA)$ in conjunction with the refined thickness indicates that between one and two layers were bound to the $\mathrm{Si}$ wafer. These results point to a multilayer structure being produced by radical initiated reactions of the diene 5 with the alkene-terminated monolayer surface. Radical induced polymerization of an alkene-terminated trichlorosilane SAM has been reported by McIntire et al., ${ }^{57}$ although in this instance the polymerization followed ozone oxidation of the monolayer surface.

\section{Adsorption of water on self-assembled surfaces}

$\mathrm{X}$-ray reflectivity data were collected as a function of exposure time on monolayer surfaces SAM-1-SAM-7. Fig. 2(a) shows a series of such data for $\mathrm{Si}-\left(\mathrm{CH}_{2}\right)_{10}-\mathrm{COOH}$ (SAM-5), with the red curve collected within the first $1 \frac{1}{2}$ hours of exposure to air and the black curve collected 48 hours after exposure. The movement of the minima in the Kiessig fringe to lower $Q$ with time indicates an increase in the thickness of the water layer that is adsorbed to the surface. As the SLD of the adsorbed water layer was found to be essentially the same as that of the underlying SAM, each set of X-ray reflectivity data were able to be successfully fitted using a single-layer model to describe the combined structure. ${ }^{58} \mathrm{We}$ found no evidence for an underlying native oxide layer from these data, and there was no significant improvement to the quality of the fit obtained by representing the adsorbed water layer as an additional layer in the model on top of the COOH-terminated SAM.

Fig. 2(b) shows an equivalent series of X-ray reflectivity data for the alkyne-terminated SAM-6, indicating an increase in the thickness after 46 hours of the adsorbed water layer by 6.3(1) $\AA$ (gray data) compared to the freshly exposed surface after $1 \frac{1}{2}$ hours (black data). The brown reflectivity profile was taken from the same sample after exposure to ambient conditions for 15 days. These latter data were unable to be adequately fitted using a single layer model to represent both the alkyne monolayer and the adsorbed water layer, indicating a significant difference in the electron density between the adsorbed water layer and the underlying SAM. A two layer model gave a very good fit 
Table 1 Measured water contact angles, refined structural parameters and fitted water adsorption kinetics based on X-ray reflectivity data

\begin{tabular}{|c|c|c|c|c|c|c|c|c|c|c|}
\hline \multirow[b]{2}{*}{ Surface } & \multirow[b]{2}{*}{ Functionality } & \multicolumn{6}{|c|}{ Refined structural parameters from XRR } & \multicolumn{3}{|c|}{$\begin{array}{l}\text { Water adsorption } \\
\text { kinetics }^{b}\end{array}$} \\
\hline & & $\begin{array}{l}\text { Contact } \\
\text { angle }^{\circ}\end{array}$ & Thickness/A & $\begin{array}{l}\text { SLD } \\
\left(\times 10^{-6} \AA^{-2}\right)\end{array}$ & $\begin{array}{l}\text { Surface } \\
\text { roughness/A }\end{array}$ & $\begin{array}{l}\text { Chain } \\
\text { angle }^{\circ}\end{array}$ & $\begin{array}{l}\text { Area per } \\
\text { molecule/ } / \AA^{2}\end{array}$ & $T_{\infty} / \AA$ & $\mathrm{A} / \mathrm{A}$ & $\tau / \mathrm{h}^{-1}$ \\
\hline SAM-1 & $\mathrm{Si}-\left(\mathrm{CH}_{2}\right)_{15} \mathrm{CH}_{3}$ & 101 & $14.3(1)$ & $12.8(1)$ & $2.9(3)$ & 49 & 20 & - & - & - \\
\hline SAM-2 & $\mathrm{Si}-\left(\mathrm{CH}_{2}\right)_{11} \mathrm{Cl}$ & 94 & $10.9(1)$ & $13.6(1)$ & $3.2(5)$ & 55 & 21 & - & - & - \\
\hline SAM-3 & $\mathrm{Si}-\left(\mathrm{CH}_{2}\right)_{11} \mathrm{NH}_{2}$ & 52 & $8.3(2)$ & $12.4(1)$ & $4.7(6)$ & 59 & 27 & 4.13 & -4.36 & 0.036 \\
\hline SAM-4 & $\mathrm{Si}-\mathrm{CH}_{2}-\mathrm{CH}\left(\mathrm{CH}_{2}\right)_{5} \mathrm{CH}=\mathrm{CH}_{2}$ & 78 & $14.2(1)$ & $11.7(1)$ & $7.1(1)$ & - & - & 4.05 & -5.36 & 0.169 \\
\hline SAM-5 & $\mathrm{Si}-\left(\mathrm{CH}_{2}\right)_{10}(\mathrm{COOH})$ & 50 & $9.8(1)$ & $11.6(1)$ & $2.5(5)$ & 59 & 25 & 6.12 & -6.75 & 0.065 \\
\hline SAM-6 & $\mathrm{Si}-\mathrm{CH}=\mathrm{CH}\left(\mathrm{CH}_{2}\right)_{5} \mathrm{C} \equiv \mathrm{CH}$ & 82 & $9.5(1)$ & $11.8(1)$ & $2.8(5)$ & 43 & 17 & 7.63 & -8.05 & 0.047 \\
\hline SAM-7 & Si-(1-nonyne-8ene) & $79^{a}$ & $12.2(1)$ & $11.0(1)$ & $3.9(5)$ & - & - & 4.10 & -4.63 & 0.067 \\
\hline
\end{tabular}

${ }^{a}$ Contact angle for SAM-7, taken from Ng et al. (ref. 39). ${ }^{b}$ Kinetic data fitted by the expression: $T=T_{\infty}+A \exp (-\tau \times t)$.

$\left(\chi^{2}=0.005\right)$ to the observed data, with the lower layer consistent with the alkyne monolayer $(9.6(1) \AA$ ) and the upper water layer with a refined thickness of 11.4(1) $\AA$, a mass density of $0.94 \mathrm{~g}$ $\mathrm{cm}^{-3}$ and a surface roughness of $\sigma=4.9$ (2) $\AA$.

The increase in thickness of the adsorbed water layer determined using X-ray reflectometry for all of the monolayer surfaces as a function of time is shown in Fig. 3. SAM-6 (alkyne-terminated, purple data) and SAM-5 (COOH-terminated, red data) show the greatest adsorption, up to $\sim 7 \AA$ over 48 hours. In the case of surfaces SAM-3-SAM-7, the increase in thickness of the adsorbed water layer with time was modelled by the function:
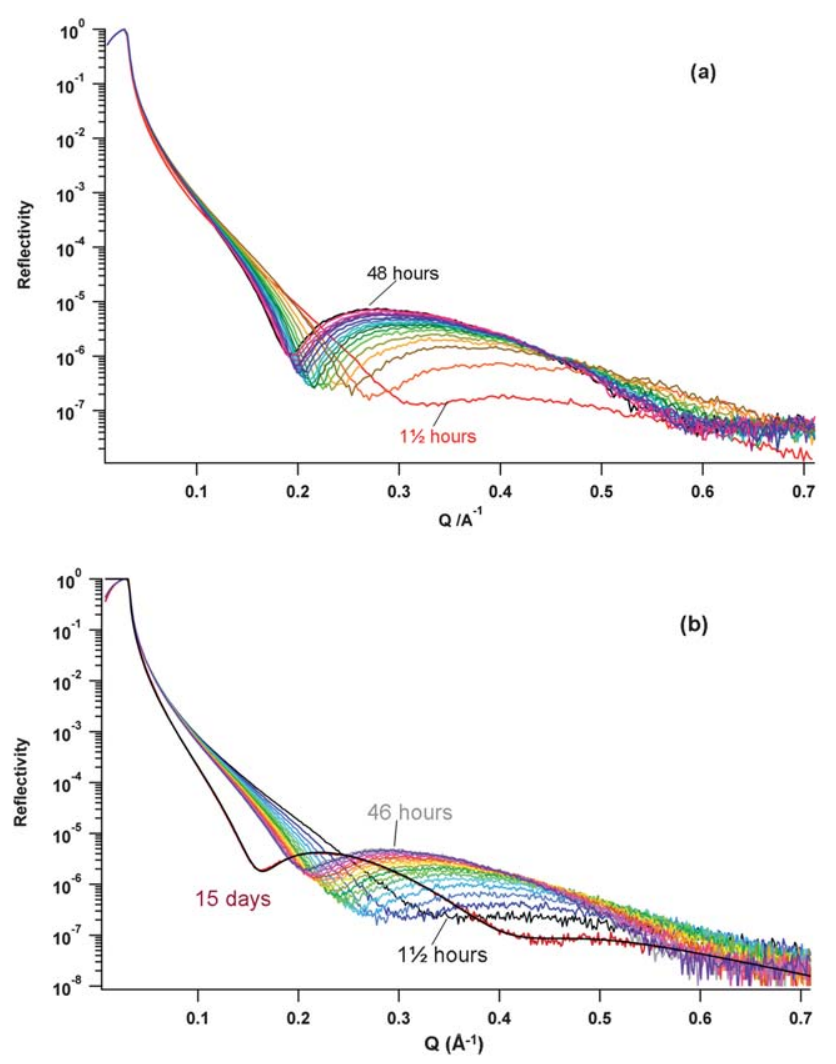

Fig. 2 X-ray reflectivity profiles from (a) $\mathrm{Si}-\left(\mathrm{CH}_{2}\right)_{10} \mathrm{COOH}$ (SAM-5) and (b) $\mathrm{Si}-\mathrm{CH}=\mathrm{CH}\left(\mathrm{CH}_{2}\right)_{5} \mathrm{C} \equiv \mathrm{CH}$ (SAM-6) as a function of time, showing an increase in thickness due to the adsorbed water.
$T=T_{\infty}+A \exp (-\tau \times t)$, where $T_{\infty}, A$ and $\tau$ are all fitting parameters and $t$ is the elapsed time in hours. $T_{\infty}$ represents the equilibrium saturation thickness for each surface and $\tau$ reflects the rate at which water is adsorbed to the surface. The fits to the observed data are shown as solid lines in Fig. 3 and the parameters derived by fitting these data for each surface are given in Table 1. The black data points provided for comparison are associated with water uptake on a freshly etched $\mathrm{Si}-\mathrm{H}$ wafer, following an initial period of several hours where the surface oxidizes to form $\mathrm{SiO}_{x}$ (see ESI $\dagger$ for further details, Fig. S7 and S8). The data shown commence $81 / 2$ hours after exposure of the $\mathrm{Si}-\mathrm{H}$ surface to ambient conditions. The dashed lines shown for the "hydrophobic" surfaces SAM-1 and SAM-2 are not fitted using the above equation, but are only guides to the eye.

A range of behaviours are observed for these self assembled monolayers (Fig. 3), with the methyl-terminated $\mathrm{Si}-\left(\mathrm{CH}_{2}\right)_{15} \mathrm{CH}_{3}$ monolayer (SAM-1, dark blue data) showing no discernible indication of water adsorption on its surface with time. In fact after 6 weeks of exposure to ambient conditions, no water was found to be present on this surface by either X-ray reflectometry or AFM. These results are consistent with molecular dynamics simulations of Szori and coworkers where no noticeable water adsorption was observed up to the point of saturation for both smooth and slightly roughened (mixtures of $-\mathrm{C}_{6} \mathrm{H}_{13} /-\mathrm{C}_{8} \mathrm{H}_{17}$ ) methyl-terminated SAMs. ${ }^{35}$ The chloro-terminated monolayer

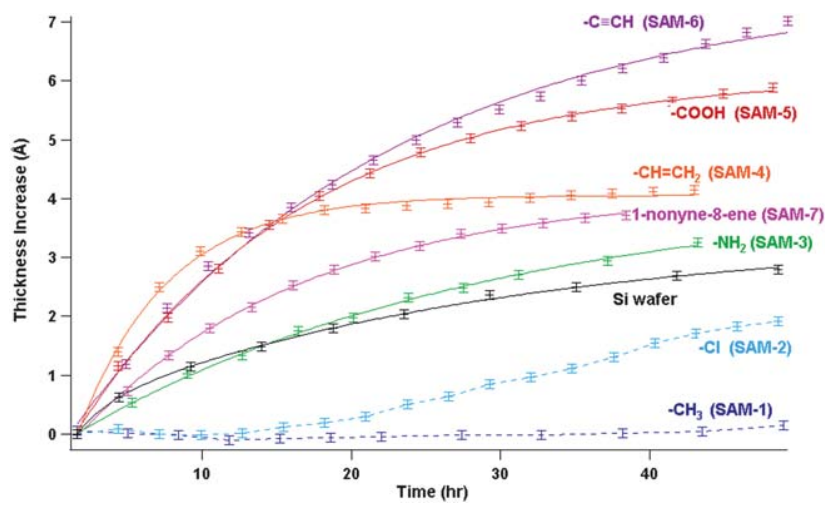

Fig. 3 The increase in thickness of the adsorbed water layer on selfassembled surfaces as a function of time determined using X-ray reflectometry. Solid lines are fits to the data, while dashed lines are guides to the eye. 
(SAM-2, light blue data) showed different behaviour to all the other surfaces, with very little adsorption apparent for the first $\sim 12$ hours, before a gradual increase in water adsorption (of 1.9 (1) A) observed over the next 36 hours. Such behaviour is however consistent with the formation of water clusters at defects on hydrophobic surfaces. ${ }^{34,59}$

The amino monolayer (SAM-3, green data) showed a modest increase in the thickness of the adsorbed water layer ( $T_{\infty}=4.13 \AA$ ). After 43 hours, SAM-3 had accumulated a water layer 3.3(1) $\AA$ in thickness, however the rate of water adsorption $\left(\tau=0.036 \mathrm{~h}^{-1}\right)$ appears to be slower than the $\mathrm{COOH}$-terminated monolayer $\left(\tau=0.065 \mathrm{~h}^{-1}\right)$. Unlike the other monolayer surfaces, formation of this amino-functionalized surface was a two-step process. The relatively poor molecular packing and increased roughness of SAM-3, along with the modest rate of water uptake for this monolayer, are suggestive of a reduced coverage of amino groups relative to the other species investigated in this study.

The alkene-terminated film (SAM-4, orange data) showed one of the highest initial rates of water adsorption $\left(\tau=0.169 \mathrm{~h}^{-1}\right)$ with $\sim 3 \AA$ after only 10 hours; however this trend did not continue and the water layer was only $4.1 \AA$ after 42 hours. Rather than a direct response to the alkene distal functionality of this surface, this result may be a reflection of the inconsistent nature of this film, with between 1 and 2 monolayers bound to the surface and a large surface roughness.

Of the monolayers derived from 1-alkene based reagents, the - $\mathrm{COOH}$ functionalized monolayer (SAM-5) revealed the largest increase in the thickness of 5.9(1) $\AA$ over 48 hours with a relatively high rate of water adsorption $\left(\tau=0.065 \mathrm{~h}^{-1}\right)$. This behaviour is quite consistent with the hydrophilic nature of this surface. The monolayer surface (SAM-6) formed from the diyne 6 and having an almost hydrophobic contact angle $\left(82^{\circ}\right)$ showed the largest amount of absorbed water for any of the surfaces studied $\left(T_{\infty}=7.63 \AA\right)$ although with a slower rate $\left(\tau=0.047 \mathrm{~h}^{-1}\right)$ than for the hydrophilic $-\mathrm{COOH}$ monolayer. This is an important and unexpected result. In addition, when one compares the kinetics of water adsorption of the alkene-terminated SAM-4 with alkyne-SAM-6, the former does not adsorb as much water. This may be a feature of the difference in attraction of water to the $\mathrm{C}=\mathrm{CH}_{2}$ and $\mathrm{C} \equiv \mathrm{CH}$ surface groups, although such an assumption should take account of the increased roughness of SAM-4 due to its multilayer structure.

SAM-7 (pink data) formed by reaction of hydride-terminated $\mathrm{Si}(100)$ with 1-nonyne-8-ene 7 showed less water adsorption ( $T_{\infty}=4.10 \AA$ ) than for the dialkyne SAM-6 and was essentially the same for the alkene-terminated SAM-4. Our previous study of SAM-7 has shown that the monolayer formed by reaction of non-1-yne-8-ene with hydrogen-terminated silicon does so with mixed functionality. ${ }^{39}$ In comparison with SAM-6, having 100\% alkyne distal functionality, SAM-7 with approximately $2 / 3$ of the distal end of the SAM having alkene functionality and 1/3 alkyne functionality, is thus expected to have weaker interactions with vapor phase water molecules.

\section{Neutron reflectometry from $\mathrm{COOH}-$ terminated monolayer}

The inability to clearly resolve the water layer from the selfassembled monolayers using X-ray reflectometry is a drawback and is essentially due to the similarity in the scattering length densities between the self-assembled monolayers and that for the adsorbed water layers (both being $\sim 1 \times 10^{-5} \AA^{-2}$ ). Neutron reflectometry therefore offers the possibility of adding clarity to the picture of the structure of the adsorbed water layer against the monolayer surface. Monolayers based purely on alkyl chains typically have small neutron scattering length densities (SLD $\approx-0.6 \times 10^{-6} \AA^{-2}$ ) and thus contrast poorly against air or $\mathrm{H}_{2} \mathrm{O}\left(\mathrm{SLD}=-0.56 \times 10^{-6} \AA^{-2}\right)$. There is however good scattering contrast with silicon (SLD $=2.07 \times 10^{-6} \AA^{-2}$ ), the alkyl chains and adsorbed water when $\mathrm{D}_{2} \mathrm{O}$ is used $\left(\mathrm{SLD}=6.36 \times 10^{-6} \AA^{-2}\right)$.

Reflectivity data collected using the Platypus neutron reflectometer from a freshly produced $\mathrm{Si}-\left(\mathrm{CH}_{2}\right)_{10}-\mathrm{COOH}$ monolayer (SAM-5) are shown in Fig. 4 under dry nitrogen ((a), red data points), and the same surface after equilibrating with $\mathrm{D}_{2} \mathrm{O}$ vapour for 72 hours ((b) blue data points). The solid lines are fits to these data based on refined structural models. The SAM surface under nitrogen was able to be fitted by a single layer model of thickness 10.1(5) $\AA$ and a scattering length density of $0.9(1) \times 10^{-6} \AA^{-2}$. Attempts to fit these neutron reflectivity data for the surface in contact with $\mathrm{D}_{2} \mathrm{O}$ vapour with a single-layer were not successful. A two-layer model was required and led to a stable refinement with a lower layer of thickness 9.5(5) $\AA$ and a SLD $=1.1(1) \times 10^{-6} \AA^{-2}$, and a distinct upper layer of thickness 5.1(7) $\AA$ and a SLD of 4.9(1) $\times 10^{-6} \AA^{-2}$.

While this enhanced scattering contrast allows us to clearly observe an adsorbed layer of $\mathrm{D}_{2} \mathrm{O}$ on the $\mathrm{COOH}$-terminated monolayer, these results also highlight the limitations of neutron reflectometry as a probe for such systems. The number of neutrons striking the sample on the Platypus reflectometer $\left(\sim 10^{4} \mathrm{~s}^{-1}\right)$ is 3-4 orders of magnitude less than the number of $\mathrm{X}$-rays striking the sample in the X-ray reflectometer; meaning that kinetic data showing the rate of moisture uptake are not available from our neutron measurements. Neutron reflectivity data also show a reduced $Q$-range due to a higher sampledependent background, associated with incoherent scattering from hydrogen present in the monolayer. This in turn limits the precision and minimum thickness that can be observed with this technique. In comparison with the model determined from X-ray

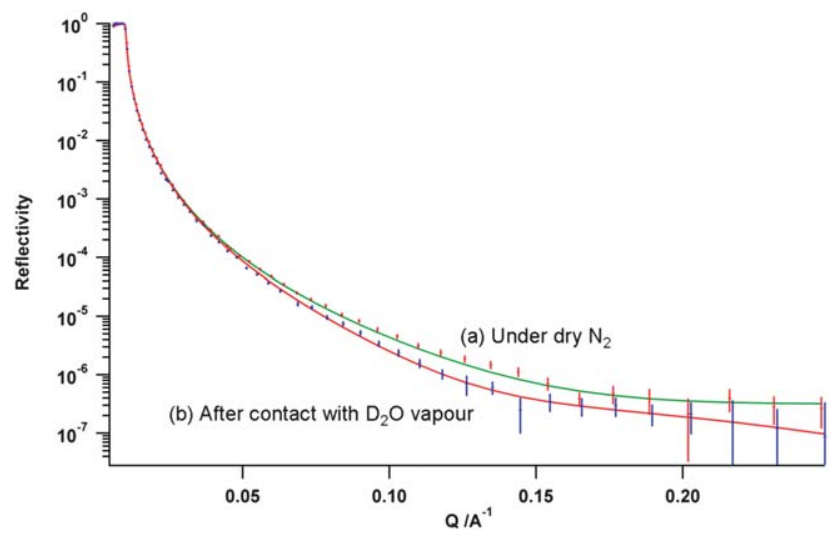

Fig. 4 Neutron reflectivity data from a freshly prepared $\mathrm{Si}-$ $\left(\mathrm{CH}_{2}\right)_{10}(\mathrm{COOH})$ monolayer (a) under dry $\mathrm{N}_{2}$, and (b) the same surface after equilibrating with $\mathrm{D}_{2} \mathrm{O}$ vapour for 72 hours. 
reflectometry for SAM-5, the density of the adsorbed $\mathrm{D}_{2} \mathrm{O}$ layer was slightly lower than expected $\left(\sim 0.85 \mathrm{~g} \mathrm{~cm}^{-3}\right)$, which may have been due to contamination by small amounts of $\mathrm{H}_{2} \mathrm{O}$.

Both neutron and X-ray reflectometry measurements show stable, high-coverage films of adsorbed water of more than a monolayer in thickness. Recently published molecular dynamics calculations by Szori and co-workers for SAMs of $-\mathrm{C}_{7}-\mathrm{COOH}$ also support this observation. ${ }^{35,36}$ For small chemical potentials (vapour pressures), water adsorption isotherms for this surface were found to increase exponentially in a continuous fashion beyond the point of saturation of the first molecular layer of water. These calculations also indicate that already adsorbed water molecules contribute to the driving force that governs the adsorption of further water molecules. Beyond a chemical potential of $-48 \mathrm{~kJ} \mathrm{~mol}^{-1}$ the rate of adsorption decreased substantially, with the observation that a stable adsorption coating of 2-5 molecular layers of water was present on the SAM prior to condensation.

\section{Monitoring moisture uptake by atomic force microscopy}

AFM images of the methyl-terminated monolayer (SAM-1) immediately after functionalization and following 6 weeks of exposure to ambient atmospheric conditions show no build-up of water on the hydrophobic surface in correspondence with our X-ray reflectivity results. In contrast, Fig. 5(a)-(d) show AFM images from the COOH-terminated monolayer (SAM-5) over a 162 hour period while being exposed to ambient atmospheric conditions. Each image shows the presence of nanoscale water droplets on the surface. Analysis of the size and distribution of these water droplets (Table 2) indicates that the height and diameter of the drops are increasing with time, while the number of drops and percentage of the surface covered by these drops are decreasing with time.

Although on a different length scale, Sommer and Pavláth ${ }^{60}$ demonstrated communication between five $10 \mu \mathrm{L}$ drops arranged on a hydrophobic surface (one central drop and four surrounding drops) over the course of 3 days. Their study showed that the central drop evaporated more slowly than the surrounding ones, and they came to the conclusion that the central drop was "irrigated" by water layers that emerged from

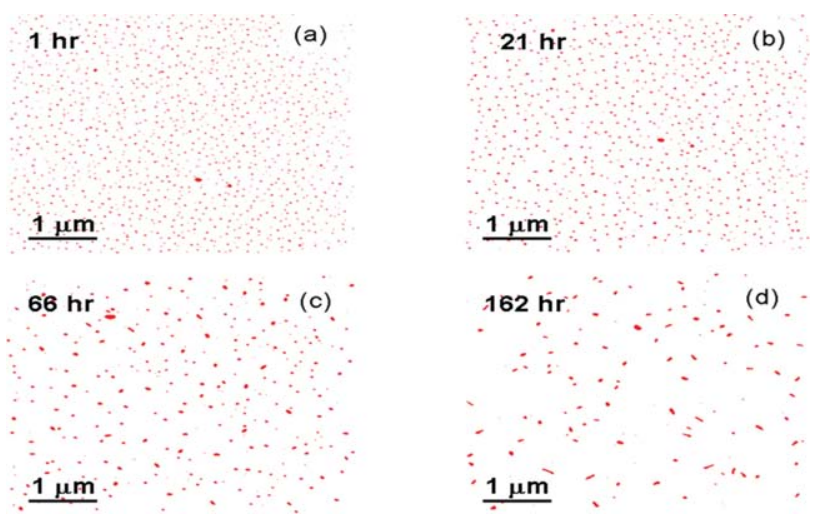

Fig. 5 Tapping mode AFM image of SAM-5, $\mathrm{Si}-\left(\mathrm{CH}_{2}\right)_{10}(\mathrm{COOH})(5 \mu \mathrm{m}$ $\times 5 \mu \mathrm{m}$ ) (a) upon exposure to air, (b) after 21 hours, (c) after 66 hours and (d) after 162 hours under ambient conditions. the collateral ones; thus influencing their relative rates of evaporation. Our AFM data also suggest the possibility of communication between the nanoscale droplets on the hydrophilic surface of SAM-5. An underlying water layer is clearly present, and although the growth in size of the droplets may be due to further water adsorption from the atmosphere, the decrease in the number of observed droplets may point to a communication process between droplets (akin to Ostwald ripening in water in oil emulsions) or even coalescence.

Comparison of these data with X-ray and neutron reflectivity data however illustrate distinct aspects of the nanoscale adsorbed water. After 42 hours, AFM data indicate an average height of these water droplets of $29 \AA$ and a surface coverage of $\sim 1.8 \%$. X-ray reflectivity data on the other hand show a $5.7 \AA$ thick water film on SAM-5 after 42 hours. Moreover, the scattering length densities of the adsorbed water layer reveal complete coverage of the surface within this layer, which is thinner than the observed water droplets. When one considers the low percentage surface coverage of the nanodroplets, it is apparent that these reflectometry techniques are not sensitive to their presence. Thus, an overall picture of this hydrophilic surface emerges from the combination of these techniques (Fig. 6): a dense, continuous water layer in contact with the $\mathrm{COOH}$ self-assembled monolayer, with a relatively small area covered by nanoscale water droplets at the air interface that get fewer in number and grow larger with time.

These results indicating the presence of nanoscale water droplets on top of a continuous thin water layer are significant. They experimentally confirm recent studies by Wang and co-workers where molecular dynamics simulations suggested the possibility at room temperature of the formation of stable liquid water droplets on an ordered water monolayer on top of a hydrophilic surface (i.e. water that does not wet a water monolayer). ${ }^{61,62}$ Their simulations suggested an average thickness of the continuous water layer of $\sim 4 \AA$ and droplets of $\sim 30 \AA$; essentially the same as those features observed by X-ray reflectometry and AFM respectively for our hydrophilic surfaces. They attributed this behaviour to the structure of the ordered water layer, where the number of hydrogen bonds within the monolayer was greatly enhanced. This in turn reduced the likelihood of hydrogen bond formation between water molecules within the layer and the other adsorbed molecules. Furthermore, their studies indicated that an appropriate charge quantity and distribution were necessary to provide strong Coulomb interactions to counteract the effects of thermal fluctuations.

In addition, the most recent MD simulation from this group has suggested the presence of irregular (non-circular) water

Table 2 Average structural parameters observed for nanoscale water droplets on SAM-5 $\mathrm{Si}-\mathrm{C}_{10} \mathrm{H}_{20}(\mathrm{COOH})$, determined by tapping mode AFM

\begin{tabular}{|c|c|c|c|c|}
\hline $\begin{array}{l}\text { Time after } \\
\text { exposure/hours }\end{array}$ & $\begin{array}{l}\text { Number } \\
\text { of drops }\end{array}$ & Diameter/Å & Height $/ \AA$ & Coverage $(\%)$ \\
\hline 0 & 1339 & 201 & 20 & 1.9 \\
\hline 21 & 878 & 254 & 25 & 2.0 \\
\hline 42 & 604 & 289 & 29 & 1.8 \\
\hline 66 & 343 & 351 & 34 & 1.7 \\
\hline 162 & 139 & 461 & 39 & 1.1 \\
\hline
\end{tabular}




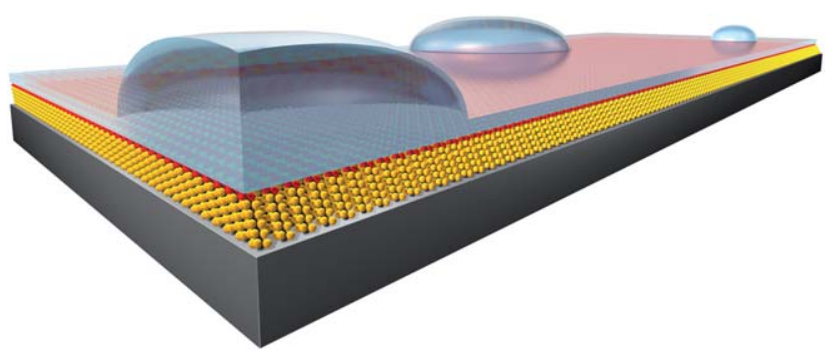

Fig. 6 (Not to scale) The overall picture of adsorbed nanoscale water on a COOH-terminated monolayer (SAM-5), indicating a continuous water layer and nanoscale droplets on a small fraction of the surface.

droplets on surfaces where low levels of defects partially disrupt the two-dimensional hydrogen bond network within the continuous water layer. ${ }^{62}$ AFM data in Fig. 5 do indeed support these simulations with the clear observation of numerous water droplets with irregular shape.

\section{Water adsorption versus temperature}

Water adsorption on the alkyne-functionalized monolayer (SAM-6) was examined under different ambient temperatures. This surface had been exposed to air for two weeks prior to these measurements. X-ray reflectivity data were measured for this surface prior to heating, revealing a total thickness of $19.4 \AA$, suggesting an adsorbed water layer of almost $10 \AA$. The surface was then heated to $100{ }^{\circ} \mathrm{C}$ and $\mathrm{X}$-ray reflectivity data collected every 36 minutes. Fig. 7(a) shows the decrease in thickness with time as the adsorbed water evaporates from the surface, ultimately leading to a moisture-free alkyne surface after 13 hours. Curves (b) and (c) in Fig. 7 show the decrease in thickness of the adsorbed water layer on this surface when heated at $80^{\circ} \mathrm{C}$ and $65^{\circ} \mathrm{C}$ respectively. When heated at $80^{\circ} \mathrm{C}$, the total film thickness decreased from $15.3 \AA$ to a dry film $(10.1 \AA)$ over $11 \frac{1 / 2}{2}$ hours, drying at a slower rate than when heated at $100{ }^{\circ} \mathrm{C}$. Heating at $65^{\circ} \mathrm{C}$ saw the total film thickness decrease from $15.4 \AA$ to $11.5 \AA$ over 14 hours, and heating for longer periods of time did not lead to a further decrease in the thickness of the adsorbed water layer.

The amount of water adsorbed on a dry alkyne surface at a given temperature was also investigated. A dry sample (with a

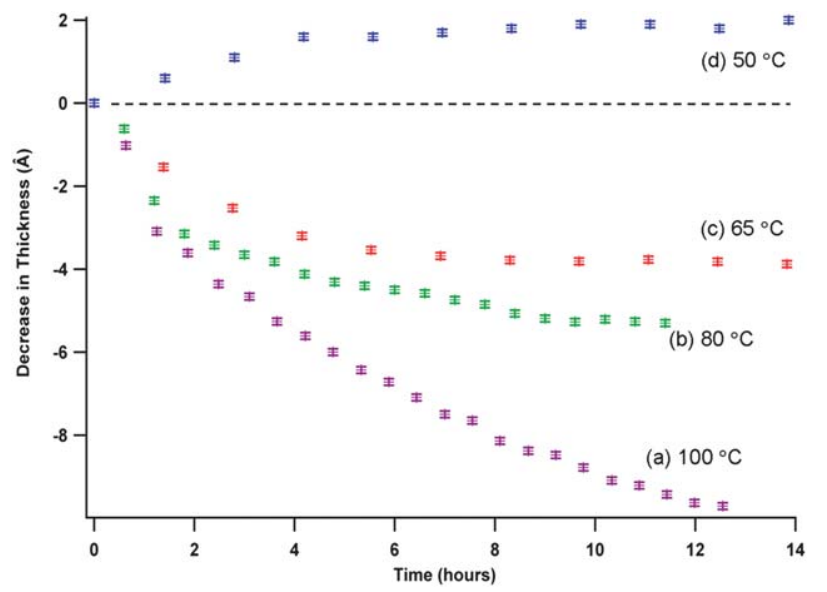

Fig. 7 The change in thickness of the adsorbed water layer on an alkyneterminated monolayer (SAM-6) as a function of temperature. total film thickness of $9.7 \AA$ ) was heated at $65^{\circ} \mathrm{C}$ for 20 hours, with the total film thickness showing essentially no increase during that time (data not shown). The same heating process conducted on a dry film at $50{ }^{\circ} \mathrm{C}$ for 18 hours showed a marginal increase from $9.5 \AA$ to $10.4 \AA$ (Fig. 7(d)).

\section{Vacuum treatment of wet monolayer surfaces}

An alkyne-terminated monolayer (SAM-6) was exposed to ambient conditions for several days, before collection of an X-ray reflectivity profile (Fig. S9(a), ESI $\dagger$ ). Analyses of these data using a single layer model indicate a densely packed monolayer $\left(\mathrm{SLD}=11.0(1) \times 10^{-6} \AA^{-2}\right.$ ) with $\sim 7 \AA$ of adsorbed water. Following evacuation in a vacuum chamber for 20 hours (achieving a minimum pressure of $\sim 2 \times 10^{-5} \mathrm{mbar}$ ), the sample was removed and the $\mathrm{X}$-ray reflectivity profile re-measured under ambient conditions (Fig. S9(b), ESI $\dagger$ ). These data show substantially different behaviour following exposure to vacuum. The total film thickness increased to 24.7(1) $\AA$, suggesting a water film thickness of $\sim 15 \AA$, and an increased SLD $(13.8(1) \times$ $10^{-6} \AA^{-2}$ ). Vacuum was thus unable to remove the adsorbed water from this hydrophilic surface at room temperature. In a similar fashion to the behaviour of bulk water in a vacuum chamber that outgases before freezing, nanoscale water also appears to freeze on these hydrophilic surfaces at room temperature. The significant increase in thickness of the water layer may be due to the collapse of nanoscale water droplets on the surface to form a continuous layer, or additional condensation of water upon removal of the atmosphere from the vacuum chamber. Previous studies have shown that water layers can strongly adsorb to hydrophilic SAMs even under ultra-high vacuum conditions. Although at $90 \mathrm{~K}$, the study by Zubavichus et $a l .{ }^{63}$ demonstrated that 7 monolayers of ice-like water were adsorbed onto a hydrophilic pyridine SAM (contact angle $30^{\circ}$ ) after 15 hours. Subsequent annealing of this surface at $57{ }^{\circ} \mathrm{C}$ under ultra-high vacuum conditions for 15 minutes was sufficient to remove most but not all of the adsorbed water from the ice layer.

\section{Correlation between water contact angles and nanoscale moisture adsorption}

Although contact angle measurements reveal the macroscopic interaction of water for a given surface, they do not necessarily clearly indicate the nature of complex interactions at the molecular level. When the fitted kinetic data for the water adsorption on these surfaces are compared to measured water contact angles (Fig. 8), the agreement is in general relatively good. The classically hydrophobic surfaces show little if any water adsorption. Surfaces SAM-3, SAM-4, SAM-5 and SAM-7 show a correlation between decreasing contact angle and increasing equilibrium saturation thicknesses $\left(T_{\infty}\right)$. The SAM-6 having alkyne functionality however clearly lies outside this expected trend.

As recently highlighted by Granick and Bae ${ }^{64}$ "hydrophobicity depends on the eye of the beholder" and that the accepted designation of hydrophobic surfaces as those possessing a contact angle larger than $90^{\circ}$ is "...just a convenient but arbitrary definition". As with much of the literature pertaining to the 
interaction of water with surfaces, some aspects of our own study support this notion. We found that a methyl-terminated SAM (SAM-1) with a classically hydrophobic contact angle of $101^{\circ}$ showed no water adsorption (according to both AFM and X-ray reflectivity), even after exposure to ambient conditions for several weeks. Other studies of "hydrophobic", methyl-terminated $\mathrm{SAMs}^{32,57,63}$ reveal the presence of adsorbed water as clusters or microdroplets, although these may have been associated with defects in the studied monolayers.

While having comparable water contact angles, the chlorineterminated monolayer (SAM-2, 94 ${ }^{\circ}$ ) and the acetylene-terminated monolayer (SAM-6, 82 ${ }^{\circ}$ ) show substantially different water adsorption at the molecular level. In both instances highquality, smooth and dense SAMs with excellent molecular packing were observed. In the case of SAM-6 in particular, there is no evidence to support the notion of water adsorption on this almost hydrophobic surface being associated with defects in the self-assembled monolayer. In addition, the density of the adsorbed water (from X-ray reflectivity measurements) is consistent with a continuous layer as opposed to clusters or microdroplets on this surface.

Sumner et al. investigated the water uptake on a range of hydrophilic and hydrophobic surfaces using Fourier transform infrared spectroscopy (FITR) in conjunction with AFM and contact angle measurements. ${ }^{65}$ They observed significant water uptake on films made of halocarbon wax and Teflon on glass despite contact angle measurements indicating that these surfaces were classically hydrophobic. While AFM measurements indicated that these surfaces were rough (with surface roughness values of $145 \AA$ and $160 \AA$ respectively), their characterization of a much smoother hydrophobic n-octyltrichlorosilane SAM also revealed small amounts of adsorbed water. Their halocarbon wax film revealed a similar exponential increase in the amount of adsorbed water with time as with our study, albeit on a different timescale. Saturation times ranged from approximately 30 minutes to more than 2 hours for relative humidity values of $77 \%$ and above. Both hydrophobic and hydrophilic surfaces showed increased amounts of adsorbed water with increased relative humidity.

Recent molecular dynamics calculations have shown quite different adsorption behaviours depending on the amount of

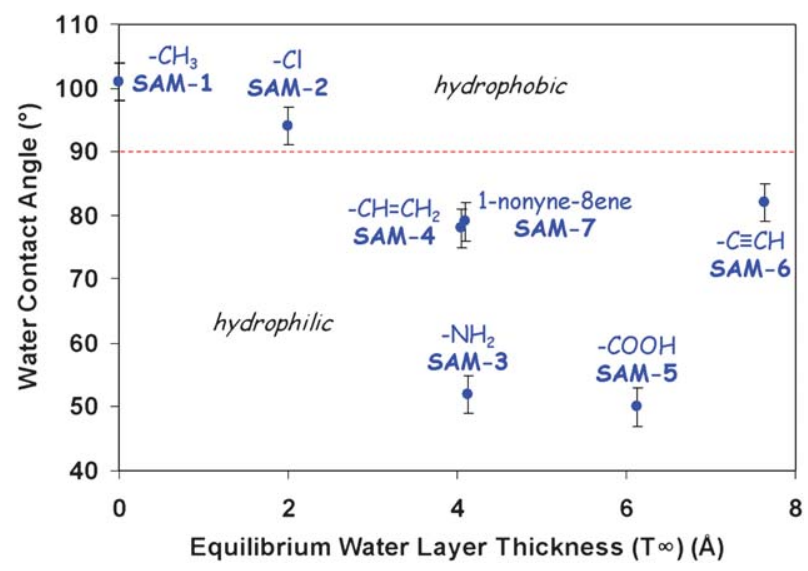

Fig. 8 Water contact angle values versus equilibrium water layer thickness $\left(T_{\infty}\right)$. water present and also the hydrophilicity of mixed monolayers with $-\mathrm{CH}_{3}$ and $-\mathrm{COOH}$ functionalities. ${ }^{36}$ As the water content was increased on SAMs with high levels of $-\mathrm{COOH}$ groups, flat domains of adsorbed water were formed, spread over the surface and eventually bridged the hydrophobic areas of the monolayer. For monolayers with a small fraction of $-\mathrm{COOH}$ groups, hydrophilic areas served as nucleation sites for the growth of water droplets while the rest of the surface remained free of adsorbed water.

\section{Conclusions}

Through a combination of surface sensitive techniques we have shown that under ambient conditions water accumulates at the molecular level on apparently dry, highly packed self-assembled monolayers. Continued observation of freshly exposed surfaces using X-ray reflectivity has allowed us to quantify the kinetics and equilibrium quantity of adsorbed water on these surfaces. When used in concert with atomic force microscopy we see a picture of nanoscale water based on a dense adsorbed water layer that builds-up over tens of hours, along with nanoscale water droplets that grow in size over a comparable timeframe.

Aside from the vital interest in understanding fundamental molecular interactions of adsorbed water from the atmosphere with these surfaces, this study must serve as a warning to others about taking adequate care with sample preparation and handling during structural investigations of surface bound molecular species. The key to enabling sophisticated characterizations using techniques such as X-ray and neutron reflectometry is to ensure these molecular surfaces avoid even trace amounts of water vapour. With the exception of the most hydrophobic self-assembled monolayers, great care must be taken to present only fresh surfaces for characterisation using $\mathrm{X}$-ray reflectometry. While drying self-assembled monolayer surfaces is relatively easy, either by rinsing with dry organic solvents or by heating to temperatures in excess of $\sim 70{ }^{\circ} \mathrm{C}$, keeping them dry is far more challenging and requires glove-box conditions (water vapour levels $<1 \mathrm{ppm}$ ). Finally, we have demonstrated that one must treat with quite significant caution the results of water contact angle measurements when assessing the propensity of self-assembled and functionalized surfaces to adsorb water at the molecular level.

\section{Acknowledgements}

The authors wish to acknowledge the assistance of Drs Ken Short and Gerry Triani. This research was supported by the Australian Research Council's Discovery Projects funding scheme (project number DP01094564). S.C. was supported by an International Postgraduate Research Scholarship from the Australian Government and by a Research Postgraduate Award from the Australian Institute of Nuclear Science and Engineering (AINSE).

\section{Notes and references}

1 S. Flink, F. C. J. M. van Veggel and D. N. Reinhoudt, Adv. Mater., 2000, 12, 1315-1328.

2 D. K. Aswal, S. Lenfant, D. Guerin, J. V. Yakhmi and D. Vuillaume, Anal. Chim. Acta, 2006, 568, 84-108. 
3 Y. Levy and J. N. Onuchic, Annu. Rev. Biophys. Biomol. Struct., 2006, 35, 389-415.

4 H. I. Kim, J. G. Kushmerick, J. E. Houston and B. C. Bunker, Langmuir, 2003, 19, 9271-9275.

5 J. Zheng, L. Li, S. Chen and S. Jiang, Langmuir, 2004, 20, 8931-8938. 6 A. E. Ismail, G. S. Grest and M. J. Stevens, Langmuir, 2007, 23, 8508 8514.

7 M. Morra, J. Biomater. Sci., Polym. Ed., 2000, 11, 547-569.

8 P. Harder, M. Grunze, R. Dahint, G. M. Whitesides and P. E. Laibinis, J. Phys. Chem. B, 1998, 102, 426-436.

9 D. J. Vanderah, H. La, J. Naff, V. Silin and K. A. Rubinson, J. Am. Chem. Soc., 2004, 126, 13639-13641.

10 L. Li, S. Chen, J. Zheng, B. D. Ratner and S. Jiang, J. Phys. Chem. B, 2005, 109, 2934-2941.

11 J. Israelachvili and H. Wennerström, Nature, 1996, 379, 219-225.

12 A. Verdaguer, G. M. Sacha, H. Bluhm and M. Sakmeron, Chem. Rev., 2006, 106, 1478-1510.

13 D. Schwendel, T. Hayashi, R. Dahint, A. Pertsin, M. Grunze, R. Steitz and F. Schreiber, Langmuir, 2003, 19, 2284-2293.

14 M. Mezger, S. Schöder, H. Reichert, H. Schröder, J. Okasinski, V. Honkimäki, J. Ralston, J. Bilgram, R. Roth and H. Dosch, J. Chem. Phys., 2008, 128, 244705.

15 A. Faucheux, A. C. Gouget-Laemmel, C. H. de Villeneuve, R. Boukherroub, F. Ozanam, P. Allongue and J.-N. Chazalviel, Langmuir, 2006, 22, 153-162.

16 T.-D. Li, J. Gao, R. Szoszkiewicz, U. Landman and E. Riedo, Phys. Rev. B: Condens. Matter Mater. Phys., 2007, 75, 115415.

17 R. C. Major, J. E. Houston, M. J. McGrath, J. I. Siepmann and X.-Y. Zhu, Phys. Rev. Lett., 2006, 96, 177803-1-177803-4.

18 M. P. Goertz, J. E. Houston and X.-Y. Zhu, Langmuir, 2007, 23, 5491-5497.

19 S. Ye, S. Nihonyanagi and K. Uosaki, Chem. Lett., 2000, 29, 734-735.

20 S. Ye, S. Nihonyanagi and K. Uosaki, Phys. Chem. Chem. Phys., 2001, 3, 3463-3469.

21 A. J. Hopkins, C. L. McFearin and G. L. Richmond, Curr. Opin. Solid State Mater. Sci., 2005, 9, 19-27.

22 C. Howell, R. Maul, W. Wenzel and P. Koelsch, Chem. Phys. Lett., 2010, 494, 193-197.

23 D. Janssen, R. De Palma, S. Verlaak, P. Heremans and W. Dehaen, Thin Solid Films, 2006, 515, 1433-1438.

24 D. J. Tiani, H. Yoo, A. Mudalige and J. E. Pemberton, Langmuir, 2008, 24, 13483-13489.

25 M. J. Stevens and G. S. Grest, Biointerphases, 2008, 3, FC13-FC22.

26 A.-C. Yang and C.-I. Weng, J. Chem. Phys., 2008, 129, 154710.

27 X. H. Zhang, N. Maeda and V. S. J. Craig, Langmuir, 2006, 22, 50255035.

28 M. P. Goertz and N. W. Moore, Prog. Surf. Sci., 2010, 85, 347-397.

29 C. Spagnoli, K. Loos, A. Ulman and M. K. Cowman, J. Am. Chem. Soc., 2003, 125, 7124-7128.

30 B. Lange, R. Posner, K. Pohl, C. Thierfelder, G. Grundmeier, S. Blankenburg and W. G. Schmidt, Surf. Sci., 2009, 603, 60-64.

31 P. L. Silvestrelli, F. Toigo and F. Ancilotto, J. Phys. Chem. B, 2006, 110, 12022-12028.

32 D. B. Asay and S. H. Kim, J. Chem. Phys., 2006, 124, 174712.

33 D. B. Asay and S. H. Kim, J. Phys. Chem. B, 2005, 109, 16760-16763.

34 Y. Rudich, I. Benjamin, R. Naaman, E. Thomas, S. Trakhtenberg and R. Ussyshkin, J. Phys. Chem. A, 2000, 104, 5238-5245.

35 M. Szori, P. Jedlovszky and M. Roeselová, Phys. Chem. Chem. Phys., 2010, 12, 4604-4616.

36 M. Szori, D. J. Tobais and M. Roeselová, J. Phys. Chem. B, 2009, 113, 4161-4169.

37 L. M. Siewierski, W. J. Brittain, S. Pertash and M. D. Foster, Langmuir, 1996, 12, 5838-5844.
38 S. O. Sylvester, Honours Thesis, University of New South Wales, 2009.

39 A. Ng, S. Ciampi, M. James, J. B. Harper and J. J. Gooding, Langmuir, 2009, 25, 13934-13941.

40 S. Ciampi, T. Böcking, K. A. Kilian, M. James, J. B. Harper and J. J. Gooding, Langmuir, 2007, 23, 9320-9329.

41 S. Ciampi, P. K. Eggers, G. Le Saux, M. James, J. B. Harper and J. J. Gooding, Langmuir, 2009, 25, 2530-2539.

42 S. Ciampi, J. B. Harper and J. J. Gooding, Chem. Soc. Rev., 2010, 39, 2158-2183.

43 T. Böcking, M. James, H. G. L. Coster, T. C. Chilcott and K. D. Barrow, Langmuir, 2004, 20, 9227-9235.

44 E. L. S. Wong, M. James, T. C. Chilcott and H. G. L. Coster, Surf. Sci., 2007, 601, 5740-5743.

45 T. Böcking, E. L. S. Wong, M. James, J. S. Watson, C. L. Brown, T. C. Chilcott, K. D. Barrow and H. G. L. Coster, Thin Solid Films, 2006, 515, 1857-1863.

46 S. Ciampi, G. Le Saux, J. B. Harper and J. J. Gooding, Electroanalysis, 2008, 20, 1513-1519.

47 A. F. Stalder, T. Melchior, M. Müller, D. Sage, T. Blu and M. Unser, Colloids Surf., A, 2010, 364, 72-81.

48 XPS atomic sensitivities were 10.82 for $\mathrm{Fe} 2 \mathrm{p} 3 / 2,5.6$ for $\mathrm{Fe} 2 \mathrm{p} 1 / 2,0.82$ for Si $2 \mathrm{p}, 1.00$ for $\mathrm{C} 1 \mathrm{~s}$ and 1.80 for $\mathrm{N} 1 \mathrm{~s}$.

49 A. Nelson, J. Appl. Crystallogr., 2006, 39, 273-276.

50 M. James, A. Nelson, A. Brule and J. C. Schulz, J. Neutron Res., 2006, 14, $91-108$.

51 M. James, A. Nelson, S. A. Holt, T. Saerbeck, W. A. Hamilton and F. Klose, Nucl. Instrum. Methods Phys. Res., Sect. A, 2011, 632, $112-123$.

52 H. Ohnukia, M. Izumia, S. Lenfant, D. Guerin, T. Imakubo and D. Vuillaume, Appl. Surf. Sci., 2005, 246, 392-396.

53 S. Lenfant, D. Guerin, F. Tran Van, C. Chevrot, J. P. Bourgoin, O. Bouloussa, F. Rondelez and D. Vuillaume, J. Phys. Chem. B, 2006, 110, 13947-13958.

54 M. R. Linford, P. Fenter, P. M. Eisenberger and C. E. D. Chidsey, J. Am. Chem. Soc., 1995, 117, 3145-3155.

55 L. Scheres, M. Giesbers and H. Zuilhof, Langmuir, 2010, 26, 10924 10929.

56 M. Halik, H. Klauk, U. Zschieschang, G. Schmid, C. Dehm, M. Schutz, S. Maisch, F. Effenberger, M. Brunnbauer and F. Stellacci, Nature, 2004, 431, 963-966.

57 T. M. McIntire, A. S. Lea, D. J. Gaspar, N. Jaitly, Y. Dubowski, Q. Lia and B. J. Finlayson-Pitts, Phys. Chem. Chem. Phys., 2005, 7, 3605-3609.

58 It should be noted that the term "single-layer" refers to the entire structure of a SAM or SAM + adsorbed water layer. This term does not indicate a single layer of adsorbed water molecules.

59 S. G. Moussa, T. M. McIntire, M. Szőri, M. Roeselová, D. J. Tobias, R. L. Grimm, J. C. Hemminger and B. J. Finlayson-Pitts, J. Phys. Chem. A, 2009, 113, 2060-2069.

60 A. P. Sommer and A. E. Pavláth, Cryst. Growth Des., 2007, 7, $18-24$.

61 C. Wang, H. Lu, Z. Wang, P. Xiu, B. Zhou, G. Zuo, R. Wan, J. Hu and H. Fang, Phys. Rev. Lett., 2009, 103, 137801.

62 C. Wang, B. Zhou, P. Xiu and H. Fang, J. Phys. Chem. C, 2011, 115, 3018-3024.

63 Y. Zubavichus, M. Zharnikov, Y. Yang, O. Fuchs, E. Umbach, C. Heske, A. Ulman and M. Grunze, Langmuir, 2004, 20, 1102211029.

64 S. Granick and S. C. Bae, Science, 2008, 322, 1477-1478.

65 A. L. Sumner, E. J. Menke, Y. Dubowski, J. T. Newberg, R. M. Penner, J. C. Hemminger, L. M. Wingen, T. Brauers and B. J. Finlayson-Pitts, Phys. Chem. Chem. Phys., 2004, 6, 604-613. 